\title{
Hemoglobin Level and Associated Factors among Pregnant Women in Rural Southwest Ethiopia
}

\author{
Melesse Niguse Kuma $\mathbb{D}^{1},{ }^{1}$ Dessalegn Tamiru $\mathbb{D}^{1},{ }^{1}$ and Tefera Belachew ${ }^{1,2}$ \\ ${ }^{1}$ Department of Nutrition and Dietetics, Jimma University, Jimma, Ethiopia \\ ${ }^{2}$ School of Graduate Studies, Jimma University, Jimma, Ethiopia \\ Correspondence should be addressed to Melesse Niguse Kuma; meleseniguse@gmail.com
}

Received 12 March 2021; Revised 4 May 2021; Accepted 8 May 2021; Published 20 May 2021

Academic Editor: Andrea Maugeri

Copyright (C) 2021 Melesse Niguse Kuma et al. This is an open access article distributed under the Creative Commons Attribution License, which permits unrestricted use, distribution, and reproduction in any medium, provided the original work is properly cited.

\begin{abstract}
Background. Anemia is a situation in which the number and size of red blood cells, or the concentration of hemoglobin, fall below established cut-off values. Low hemoglobin level during pregnancy favors the alteration of placental angiogenesis and resulted in restricting the availability of nutrients to the fetus and consequently causing fetal growth retardation and low weight at birth. This study is aimed at assessing the hemoglobin level and associated factors among pregnant women in rural communities of Jimma zone, Southwest Ethiopia. Methods. A community-based cross-sectional study design was carried out among 367 pregnant women from June 1 to 30, 2020. Systematic random sampling was used to select study subjects. Hemoglobin level was measured by using HemoCue HB 301. An interviewer-administered structured questionnaire was used to collect the data. Descriptive statistics were used to describe the study subjects. A multivariable linear regression model was employed after the linearity, normality, multicollinearity, and homoscedasticity assumptions were checked. The unstandardized beta $(\beta)$ coefficient along with a $95 \%$ confidence interval was computed to estimate the association between explanatory and dependant variables. Statistical significance was declared at $P$ value $<0.05$. Results. The mean $( \pm \mathrm{SD})$ hemoglobin level of the respondents was 12.66 $( \pm 1.44) \mathrm{g} / \mathrm{dl}$. The overall magnitude of anemia (hemoglobin level $<11 \mathrm{~g} / \mathrm{dl}$ ) among pregnant women was found to be $85[23.16 \%$, (95\% CI: $18.3 \%-27.5 \%)$. Meal frequency [ $\beta=0.40,(95 \% \mathrm{CI}: 0.12,0.69), P=0.005]$, interpregnancy interval $[\beta=0.08,(95 \% \mathrm{CI}$ : $0.02,0.15), \quad P=0.007]$, mid-upper arm circumference measurement $[\beta=0.13,(95 \% \mathrm{CI}: 0.07,0.20), P \leq 0.001]$, own fruits/vegetable $[\beta=0.55$, (95\% CI: $0.79,0.31), P \leq 0.001$ ], coffee consumption [ $\beta=-1.00$, (95\% CI: $-1.31,-0.68), P \leq 0.001]$, and having history of still birth $[\beta=-0.63,(95 \% \mathrm{CI}:-1.06,-0.20), P=0.004]$ were significantly associated with the hemoglobin level of pregnant women. Conclusions. Anemia was identified to be a moderate public health problem in the study area. Therefore, nutritional counseling should focus on the necessity of at least one extra meal, promotion of fruits/vegetable consumption, and improving the nutritional status of the women during antenatal care follow-up. Moreover, early screening and management of women with a history of stillbirth for anemia are also essential.
\end{abstract}

\section{Background}

Anemia is a situation in which the number and size of red blood cells, or the hemoglobin concentration, fall below established cut-off values, consequently impairing the capacity of the blood to transport oxygen to the body [1]. The World Health Organization defined anemia during pregnancy as a hemoglobin level of $<11 \mathrm{~g} / \mathrm{dl}$ [2]. Even though measurement of blood hemoglobin concentration alone does not determine the cause of anemia, it is the reliable indicator of anemia at a population level [3]. Globally, about $38 \%$ of pregnant women are anemic of which almost two-thirds were from developing countries [3]. Low hemoglobin level or anemia in pregnancy is a public health problem associated with many adverse birth outcomes such as premature delivery, low birth weight, and increased newborn and maternal mortality $[4,5]$.

Iron deficiency anemia is the most common cause of anemia accounted for more than $50 \%$ of all types of anemia in women, resulted from prolonged negative iron balance, 
caused by poor gut absorption or inadequate dietary iron intake, increased body demand of iron during pregnancy or growth periods, and increased iron loss $[3,6]$. Iron is crucial for the fundamental metabolic process in cells and organisms' functions, including respiration, energy production, DNA production, and cell proliferation [7]. During pregnancy, low hemoglobin level favors the alteration of placental angiogenesis and resulted in restricting the availability of oxygen to the fetus and consequently causing fetal growth restriction and low birth weight [8]. Evidence has shown that there is a U-shaped curve relationship between maternal hemoglobin concentration and risk of adverse birth outcomes; however, the association varied by trimester [9]. Studies revealed that both low and high hemoglobin concentrations during pregnancy were associated with the risk of adverse birth outcomes through several mechanisms. Therefore, only an adequate supply of iron during pregnancy is essential [10]. The link between low maternal hemoglobin concentration and adverse birth outcomes is more clear when it is measured during the first trimester of pregnancy, whereas the high hemoglobin concentration is associated during all three trimesters of pregnancy [9]. To reduce this risk, WHO recommends a universal daily supplementation of oral elemental iron $30-60 \mathrm{mg}$ and folic acid $0.4 \mathrm{mg}$ as part of routine antenatal care follow-up throughout the pregnancy [11]. Studies have also witnessed that improving maternal hemoglobin level during pregnancy can reduce the risk of maternal mortality and morbidity from postpartum hemorrhage [4].

Cognizant of these, the Federal Government of Ethiopia established the national nutrition packages to improve micronutrient deficiencies among pregnant women by ensuring access to routine nutritional counseling and supplementations as dewarming, insecticide-treated nets, and ironfolic acid supplementations during perinatal care [12]. Even though considerable efforts have been made to reduce the prevalence of anemia in the country, the Ethiopia demographic health survey of 2016 indicated that $29 \%$ of pregnant women and $24 \%$ of female reproductive age groups were still anemic [13]. To attain the second global nutrition target set of a $50 \%$ decrease of anemia among reproductive age of women by the year 2025, it was agreed that a combination of key programs and strategies that are tailored to local conditions, taking into account the definite cause and frequency of anemia in a given area and group of population, is required $[1,6]$. However, there was a paucity of information that elucidates the hemoglobin level of pregnant women in lowincome countries like Ethiopia especially in the study area, rural communities. Therefore, this study is aimed at assessing the hemoglobin level and associated factors among pregnant women in rural communities of Jimma zone, Southwest Ethiopia.

\section{Methods and Materials}

2.1. Study Design, Setting, and Participants. A communitybased cross-sectional study design was carried out in Mana and Seka Chekorsa districts of Jimma zone, Southwest Ethiopia from June 1 to 30,2020 . The zone was found $345 \mathrm{~km}$ away from the capital city Addis Ababa. Jimma zone has two known agroecological (coffee growing and food crop growing) districts $[14,15]$. Accordingly, Mana was selected from mainly coffee growing districts and found at 1911 meters of/altitude above sea level with an estimated total population of 160,096, of whom 79,615 were women. The district has 26 kebeles (small administrative units) including Yebu and Bilida Towns. The other selected district was Seka Chekorsa from principal grain and food crop producing districts. It had an altitude between 1580 to 2560 meters above sea level and an estimated total population of 336,277, of whom 167,414 were females. This district has 37 kebeles including the two town kebeles of Seka. The study was conducted among first-trimester pregnant mothers 15-49 years of age.

2.2. Inclusion and Exclusion Criteria. All randomly selected first-trimester pregnant women who were living in the area at least for the last six months before the survey were included in the study. First-trimester pregnant women with known preexisting or current medical conditions were excluded.

\subsection{Sample Size Determination and Sampling Technique. The} sample size was calculated using G power 3.1 software considering the following assumptions: $t$-tests-correlation: point biserial model, two tail, effect size $|\rho|=0.15, \alpha$ err prob 0.05 , power $(1-\beta$ err prob $)=0.80$, then, the total sample size was 343. The final sample size was 378 after adding a 10\% nonresponse rate. A list of all kebeles of both districts (37 from Seka Chekorsa and 26 from Mana) was made, and a unique identification number was assigned to each. Then, this identification number was used as a sampling frame to select kebeles. From a total of 63 kebeles listed, 21 were selected by a simple random sampling method. After all, the sample size was proportionally allocated to each kebele. The sampling frame of the study participants was prepared after home to the home identification and recording of all eligible pregnant mothers. Then, first-trimester pregnant women were selected using systematic random sampling. Pregnant women who were absent from home were revisited on the next day. If a woman was still absent from her house during the interview, eligible pregnant women in the next house in the serial number were interviewed. The pregnancy was confirmed by ultrasound scanning and pregnancies that were diagnosed as nonviable or had incurable deformities were referred to the nearest health facility for management.

2.4. Data Collection Instruments, Techniques, and Measurements. The data were collected by a pretested, interviewer-administered structured questionnaire. It was collected by experienced and trained eight BSc holder midwives who could speak the local language "Afan Oromo."

2.5. Measurements of Hemoglobin Level. The hemoglobin level of women was measured by using HemoCue AB Sweden 301(HemoCue AB, Angelhom, Sweden). The machine was a precalibrated instrument designed for the measurement of hemoglobin concentration. The blood sample was collected from each participant using a figure pricking method to collect three drops of blood from the left ring finger. The first 
and second drops of blood were wiped away. Then, the third drop was used for testing the hemoglobin level. The blood was drawn through microcuvettes and inserted into the HemoCue machine, and the results were recorded.

2.6. Mid-Upper Arm Circumference Measurement. Midupper arm circumference measurement was an average of three measurements to the adjacent cent-meter using a flexible nonelastic tape. It is midway between the tip of the shoulder (acromion process) and the tip of the elbow (olecranon process) of the left arm hanging freely.

2.7. Minimum Dietary Diversity-Women (MDD-W). The data of minimum dietary diversity score were collected by using a 24-hour dietary recall method according to FAO's 2016 guideline [16]. To each food group that a woman ate in $24 \mathrm{hrs}$ of the day before data collection score of " 1 " was given and otherwise "0." The dietary diversity score was made by counting the number of scores of food groups. For one food group, only a score of " 1 " was given and sum up all without considering the number of foods eaten in the same food group. Finally, a woman who had got 5 scores or more out of ten was categorized as adequate and otherwise inadequate dietary diversity. The ten food groups used were starchy foods, pulses, nuts and seeds, milk and milk products, meat, eggs, dark green leafy vegetables, vitamin a-rich fruits and vegetables, other vegetables, and other fruits.

2.8. Data Quality Control. The questionnaire was first prepared in English and translated into the local language "Afan Oromo" by fluent speakers of both languages. Then, it was translated back to English by the third expert to ensure its consistency. To ensure the quality of data, three days of intensive training were given for data collectors and supervisors on the objective of the study, methods of data collection, anthropometric measurement, blood sample collection, and data recording methods. A practical test was administered for data collectors to make sure that the skill was appropriately transferred. In addition to this, two trained supervisors were assigned to give on-site support and oversee the completeness of the collected data overnight. A pretest was conducted on $5 \%$ of the total sample size in a nonselected setting that had similar characteristics of respondents in the Kersa district of Jimma Zone.

2.9. Data Processing and Analysis. Data were checked for consistency, accuracy, and completeness. Then, it was entered into Epi-data version 3.1 and exported to STATA version 13 for data cleaning and analysis. Data cleaning was made by checking outliers, ascending and descending order. Descriptive statistics such as central tendency measurements and variation: mean, frequency, percentages, and standard deviations were used to describe the study subjects. Major assumptions for binary and multivariable linear regression analyses were checked by examining the residuals for the linearity assumption using a scatter plot for all numerical predictor variables and the dependent variable (mean hemoglobin level). All variables were normally distributed and assessed visually using a histogram. Moreover, homoscedasticity was checked by using a scatter plot, and there was no heteroscedasticity or clear pattern on the plot. Likewise, multicollinearity was checked using a variance inflation factor, and there was no interaction. Simple linear regression analysis was performed for each independent variable against the dependent variable. Variables with $P$ value $<0.25$ were considered for multivariable linear regression analyses to control the possible effects of a confounder. Variables with a $P$ value of 0.05 were declared significantly associated with the mean hemoglobin level of women in the final adjusted multivariable linear regression model. Unstandardized beta $(\beta)$ coefficients along with $95 \%$ confidence interval (CI) were computed to assess the level of association and statistical significance in multivariable linear regression analysis. The wealth index was estimated as a composite indicator of living standards by considering 29 variables related to ownership of household durable assets (both productive and nonproductive assets). Assumptions of the principal component analysis were checked. The overall sampling adequacy $(\mathrm{KMO}>0.5)$, Bartlett's test of sphericity $(P \leq 0.05)$, having commonality $>0.5$, not having the complex structure correlation $\geq 0.40$ assumptions were checked and components that collectively explain more than $60 \%$ of the variance in the set of variables were used for generation of a continuous variable by summing up the principal components into one and tertile rank was made into rich, medium, and poor.

2.10. Ethical Consideration. Ethical approval was obtained from Jimma University Institutional Review Board (IRB) and Oromia Regional Health Bureau. A letter of permission was obtained from the Health office of Jimma Zone. After explaining the purpose and objective of the study, written informed consent and fingerprint (who were unable to read and write) were obtained from each participant. Confidentiality and privacy were kept throughout the study. Privacy of the respondents was maintained by interviewing them in an isolated room. The data were kept under a locked cabinet and were not disclosed to anyone except the investigators. The procedure constituted a minimal risk to the participants, and it was explained before the onset of the data collection process.

\section{Results}

A total of 367 pregnant women participated in the study with a response rate of $97 \%$. The mean ( $\mathrm{SD} \pm$ ) age of the respondents was $23.77( \pm 4.80)$ years. A majority $(96.73 \%)$ of the participants were Oromo by ethnicity and $90 \%$ Muslim religion followers. About half of them (48.5\%) were attended some primary school grades whereas one quarter $(21.8 \%)$ were unable to read and write. Most of the respondents (72.76\%) were housewives followed by merchants $(21 \%)$ and daily laborers (2.72\%). Almost all of the participants (99.72\%) were married. Most of the respondents (72\%) were using protected spring water for drinking. Large proportions (70.30\%) of the participants were from the medium wealth tertile. The overall magnitude of anemia (hemoglobin level $<11 \mathrm{~g} / \mathrm{dl}$ ) among pregnant women was found to be 85 [23.16\%, (95\% CI: 18.3\%-27.5\%)] (Table 1). 
TABLE 1: Sociodemographic and economic characteristics of pregnant women in rural Jimma Zone, Southwest Ethiopia, 2020, $(n=367)$.

\begin{tabular}{|c|c|c|c|c|c|}
\hline \multirow{2}{*}{ Variable } & \multicolumn{2}{|c|}{ Anemia $(<11 \mathrm{~g} / \mathrm{l})$} & \multirow{2}{*}{ Total (\%) } & \multirow{2}{*}{$X^{2}$} & \multirow{2}{*}{$P$ value } \\
\hline & No $(\%)(n=85)$ & Yes $(\%)(n=282)$ & & & \\
\hline \multicolumn{6}{|l|}{ Age in years } \\
\hline $15-20$ & $90(24.52)$ & $36(9.80)$ & $126(34.33)$ & \multirow{5}{*}{6.22} & \multirow{5}{*}{0.18} \\
\hline $21-24$ & $48(13.08)$ & $12(3.27)$ & $60(16.35)$ & & \\
\hline $25-29$ & $108(29.43)$ & $28(7.63)$ & $136(37.06)$ & & \\
\hline $30-34$ & $20(5.45)$ & $8(2.18)$ & $28(7.63)$ & & \\
\hline $35-49$ & $16(4.36)$ & $1(0.27)$ & $17(4.63)$ & & \\
\hline \multicolumn{6}{|l|}{ Ethnicity } \\
\hline Oromo & $271(73.84)$ & $84(22.89)$ & $355(96.73)$ & \multirow{4}{*}{2.18} & \multirow{4}{*}{0.70} \\
\hline Amhara & $4(1.09)$ & $1(0.27)$ & $5(1.36)$ & & \\
\hline Dawuro & $4(1.09)$ & $0(0)$ & $4(1.09)$ & & \\
\hline Yem & $3(081)$ & $0(0)$ & $3(0.81)$ & & \\
\hline \multicolumn{6}{|l|}{ Religion } \\
\hline Muslim & $250(68.12)$ & $83(22.62)$ & $333(90.74)$ & \multirow{3}{*}{6.63} & \multirow{3}{*}{0.03} \\
\hline Orthodox & $26(7.08)$ & $1(0.28)$ & $27(7.36)$ & & \\
\hline Protestant & $6(1.64)$ & $1(0.27)$ & $7(1.91)$ & & \\
\hline \multicolumn{6}{|l|}{ Maternal education } \\
\hline Unable to read and write & $59(16.07)$ & $21(5.73)$ & $80(21.80)$ & \multirow{5}{*}{1.13} & \multirow{5}{*}{0.95} \\
\hline Elementary grades & $136(37.06)$ & $42(11.44)$ & $178(48.50)$ & & \\
\hline Completed grade 8 & $42(11.44)$ & $10(2.73)$ & $52(14.17)$ & & \\
\hline High school grades & $21(5.72)$ & $5(1.36)$ & $26(7.08)$ & & \\
\hline Collage and above & $24(6.53)$ & $7(1.91)$ & $31(8.44)$ & & \\
\hline \multicolumn{6}{|l|}{ Maternal occupation } \\
\hline Merchant & $59(16.07)$ & $18(4.13)$ & $77(20.20)$ & \multirow{5}{*}{2.99} & \multirow{5}{*}{0.55} \\
\hline Housewife & $203(55.32)$ & $64(17.43)$ & $267(72.75)$ & & \\
\hline Governmental employee & $5(1.36)$ & $2(0.55)$ & $7(1.91)$ & & \\
\hline Student & $6(1.63)$ & $0(0)$ & $6(1.63)$ & & \\
\hline Daily laborer & $9(2.46)$ & $1(0.26)$ & $10(2.72)$ & & \\
\hline Marital status & & & & & \\
\hline Married & $281(76.56)$ & $85(23.16)$ & $366(99.72)$ & 030 & 058 \\
\hline Widowed & $1(0.28)$ & $0(0)$ & $1(0.28)$ & 0.30 & 0.58 \\
\hline Husband's occupation & & & & & \\
\hline Merchant & $76(20.71)$ & $21(5.72)$ & $97(26.43)$ & & \\
\hline Farmer & $122(33.25)$ & $40(10.89)$ & $162(44.14)$ & & \\
\hline Governmental employee & $18(4.9)$ & $0(0)$ & $18(4.9)$ & 10.63 & 0.10 \\
\hline Daily laborer & $57(15.53)$ & $9(2.45)$ & 66 (17.98) & & \\
\hline Private employee & $16(4.36)$ & $8(2.18)$ & $24(6.54)$ & & \\
\hline Family size & & & & & \\
\hline Less than five & $236(64.30)$ & $71(19.35)$ & $307(83.65)$ & 1001 & 097 \\
\hline Six and above & $46(12.53)$ & $14(3.82)$ & $60(16.35)$ & 0.001 & 0.97 \\
\hline Household head & & & & & \\
\hline Man & $271(73.84)$ & $83(22.62)$ & $354(96.46)$ & 045 & 049 \\
\hline Woman & $11(3.00)$ & $2(0.54)$ & $13(3.54)$ & & 0.49 \\
\hline Drinking water source & & & & & \\
\hline Public tape & $35(9.54)$ & $14(3.81)$ & $49(13.35)$ & & \\
\hline Protected spring & $206(56.13)$ & $58(15.80)$ & $264(71.93)$ & 005 & 056 \\
\hline Pipe water & $29(7.90)$ & $11(3.00)$ & $40(10.90)$ & 0.03 & 0.30 \\
\hline River & $12(3.27)$ & $2(0.54)$ & $14(3.81)$ & & \\
\hline Household wealth index & & & & & \\
\hline Rich & $21(5.72)$ & $6(1.64)$ & $27(7.36)$ & & \\
\hline Medium & $202(55.04)$ & $56(15.26)$ & $258(70.30)$ & 1.42 & 0.49 \\
\hline Poor & $59(16.08)$ & $23(6.26)$ & $82(22.34)$ & & \\
\hline
\end{tabular}


TABLE 2: Obstetrics and pregnancy-related characteristics of pregnant women in rural Jimma Zone, Southwest Ethiopia, 2020, $(n=367)$.

\begin{tabular}{|c|c|c|c|c|c|}
\hline \multirow{2}{*}{ Variable } & \multicolumn{2}{|c|}{ Anemia $(<11 \mathrm{~g} / \mathrm{l})$} & \multirow{2}{*}{ Total (\%) } & \multirow{2}{*}{$X^{2}$} & \multirow{2}{*}{$P$ value } \\
\hline & Yes $(n=85)$ & No $(n=282)$ & & & \\
\hline \multicolumn{6}{|l|}{ Gestational age } \\
\hline$<8$ weeks & $5(1.36)$ & $11(3.00)$ & $16(4.36)$ & \multirow{2}{*}{0.61} & \multirow{2}{*}{0.43} \\
\hline 8 to 13 weeks & 80 & 271 & $351(95.64)$ & & \\
\hline \multicolumn{6}{|l|}{ Inter pregnancy interval } \\
\hline$\leq 2$ years & 37 & 95 & $132(35.96)$ & \multirow{2}{*}{2.74} & \multirow{2}{*}{0.09} \\
\hline$>2$ years & 48 & 187 & $235(64.03)$ & & \\
\hline \multicolumn{6}{|l|}{ Parity of women } \\
\hline Primi Para & 26 & 79 & $105(28.61)$ & \multirow{4}{*}{4.85} & \multirow{4}{*}{0.30} \\
\hline 1-2 children & 43 & 136 & $179(48.77)$ & & \\
\hline $3-4$ children & 11 & 56 & $67(18.26)$ & & \\
\hline 5 and more children & 5 & 11 & $16(4.36)$ & & \\
\hline \multicolumn{6}{|l|}{ History of abortion } \\
\hline Yes & 12 & 59 & $71(19.35)$ & \multirow{2}{*}{1.93} & \multirow{2}{*}{0.16} \\
\hline No & 73 & 223 & $296(80.65)$ & & \\
\hline \multicolumn{6}{|l|}{ History of stillbirth } \\
\hline Yes & 9 & 22 & $31(8.45)$ & \multirow{2}{*}{0.61} & \multirow{2}{*}{0.43} \\
\hline No & 76 & 260 & $336(91.55)$ & & \\
\hline \multicolumn{6}{|c|}{ History of cesarean section } \\
\hline Yes & 1 & 8 & $9(2.45)$ & \multirow{2}{*}{0.75} & \multirow{2}{*}{0.38} \\
\hline No & 84 & 274 & $358(97.55)$ & & \\
\hline \multicolumn{6}{|l|}{ Has nausea or vomiting } \\
\hline Yes & 32 & 120 & $152(41.42)$ & \multirow{2}{*}{0.64} & \multirow{2}{*}{0.42} \\
\hline No & 53 & 162 & $215(58.58)$ & & \\
\hline
\end{tabular}

3.1. Obstetrics and Pregnancy-Related Characteristics. All of the respondents were in first-trimester pregnancy with the majority $(93.73 \%)$ of $8-13$ gestational weeks. More than half of the respondents (63.22\%) had less than two years of interpregnancy interval. Moreover, the majority of them had no history of stillbirth (91.55\%) and cesarean section (97.55\%). Less than a quarter (19.35\%) of the respondents had a history of abortion (Table 2).

3.2. Dietary Practices of Pregnant Women. More than half $(52.86 \%)$ of the respondents had fruits/vegetables in their garden either to consume or sell it. Most of the respondents (74.39\%) did not change their diet during pregnancy. Besides, $20 \%$ of them had avoided some types of foods during pregnancy because of food taboos. About $83.11 \%$ of the women did not receive iron folate supplementation during their first trimester of pregnancy. Moreover, most of the respondents consumed coffee during the current pregnancy (82.29\%) (Table 3).

3.3. Factors Associated with Maternal Hemoglobin Status. Simple linear regression analysis was performed for all independent variables. However, only ten variables, MUAC(midupper arm circumference), maternal education of completing grade 8 , interpregnancy interval, having a history of stillbirth, meal frequency, coffee consumption, iron folate supplementation, own fruits/vegetables, were linearly associated with a hemoglobin level of a woman at $P$ value $<0.05$ (Table 4 ).
The final adjusted multivariable linear regression analyses revealed that maternal hemoglobin level was positively associated with meal frequency $[\beta=0.409$, (95\% CI: 0.123 , $0.694), P=0.005]$, duration of interpregnancy interval $[\beta=0.089$, (95\% CI: $0.024,0.154), P=0.007]$, mid-upper arm circumference measurements $[\beta=0.139, \quad(95 \% \mathrm{CI}$ : $0.071,0.207), \quad P \leq 0.001]$, and having fruits/vegetables $[\beta=0.557,(95 \% \mathrm{CI}: 0.317,0.796), P \leq 0.001]$. Whereas it was negatively associated with women having a history of still birth $[\beta=-0.634,(95 \% \mathrm{CI}:-1.061,-0.208), P=0.004]$ and consuming coffee during their current pregnancy $[\beta=-1.000$, (95\% CI: $-1.317,-0.683), P \leq 0.001]$ (Table 5).

\section{Discussions}

This study revealed that the mean $( \pm$ SD) hemoglobin level of pregnant women in rural Southwest Ethiopia was 12.66 $( \pm 1.40) \mathrm{g} / \mathrm{dl}$ with a range of $9-18 \mathrm{~g} / \mathrm{dl}$. The current result obtained in this study was agreed with the findings reported in the previous studies carried out in the West Arsi Zone of Ethiopia $12.05( \pm 1.5)$ g/dl [17], Bsidimo Hospital 11.4 $( \pm 2.3) \mathrm{g} / \mathrm{dl}$ [18], Rural community of Eastern Ethiopia $11( \pm 1.7) \mathrm{g} / \mathrm{dl}[19]$, Southern Ethiopia $11.9( \pm 1.4) \mathrm{g} / \mathrm{dl}[20]$, Debremarkos Hospital 12.65 ( \pm 2.82$) \mathrm{g} / \mathrm{dl}$ [21], and Northwestern zone of Tigray region $11.21( \pm 1.8) \mathrm{g} / \mathrm{dl}$. However, it was higher than the reports from Accra, Ghana $10.9( \pm 1.3)$ g/dl [22], Karnataka, India $9.6( \pm 1.63) \mathrm{g} / \mathrm{dl}$ [23], and the Kolar Taluk district of India $10.5 \mathrm{~g} / \mathrm{dl}$ [24]. This difference 
TABLE 3: The dietary practices of pregnant women in rural Jimma Zone, Southwest Ethiopia, 2020, $(n=367)$.

\begin{tabular}{|c|c|c|c|c|c|}
\hline \multirow[b]{2}{*}{ Variable } & \multicolumn{2}{|c|}{ Anemia $(<11 \mathrm{~g} / \mathrm{dl})$} & \multirow[b]{2}{*}{ Total (\%) } & \multirow[b]{2}{*}{$X^{2}$} & \multirow[b]{2}{*}{$P$ value } \\
\hline & $\begin{array}{c}\text { Yes } \\
n=85(\%)\end{array}$ & $\begin{array}{c}\text { No } \\
n=282(\%)\end{array}$ & & & \\
\hline \multicolumn{6}{|l|}{ Own fruit/vegetable garden } \\
\hline Yes & $38(10.35)$ & $156(42.51)$ & $194(52.86)$ & \multirow{2}{*}{2.95} & \multirow{2}{*}{0.08} \\
\hline No & $47(12.81)$ & $126(34.33)$ & $173(47.14)$ & & \\
\hline \multicolumn{6}{|l|}{ Used fruit/vegetables } \\
\hline Sell all & $0(0)$ & $2(1.02)$ & $2(1.02)$ & \multirow{3}{*}{0.57} & \multirow{3}{*}{0.74} \\
\hline Sell some & $23(6.27)$ & $82(47.30)$ & $105(53.57)$ & & \\
\hline Consumed all & $20(5.45)$ & $69(39.96)$ & $89(45.41)$ & & \\
\hline \multicolumn{6}{|c|}{ Changed food habit during pregnancy } \\
\hline Yes & $26(7.08)$ & $68(18.53)$ & $94(25.61)$ & \multirow{2}{*}{1.43} & \multirow{2}{*}{0.23} \\
\hline No & $59(16.07)$ & $214(58.32)$ & $273(74.39)$ & & \\
\hline \multicolumn{6}{|c|}{ Avoid food during pregnancy } \\
\hline Yes & $19(5.18)$ & $53(14.44)$ & $72(19.62)$ & \multirow{2}{*}{0.52} & \multirow{2}{*}{0.46} \\
\hline No & $66(17.98)$ & $229(62.40)$ & $295(80.38)$ & & \\
\hline \multicolumn{6}{|l|}{ Types of foods avoided } \\
\hline Sugar cane & $9(2.46)$ & $23(41.98)$ & $32(44.44)$ & \multirow{3}{*}{0.08} & \multirow{3}{*}{0.96} \\
\hline Avocado & $5(1.36)$ & $15(25.02)$ & $20(26.39)$ & & \\
\hline Tomato & $6(1.63)$ & $15(29.54)$ & $21(29.17)$ & & \\
\hline \multicolumn{6}{|l|}{ Reason for food avoidance } \\
\hline Big baby & $16(4.35)$ & $39(72.03)$ & 55 (76.39) & \multirow{4}{*}{2.78} & \multirow{4}{*}{0.42} \\
\hline Maternal obesity & $0(0)$ & $2(2.78)$ & $2(2.78)$ & & \\
\hline Discolor the fetus & $0(0)$ & $5(6.94)$ & $5(6.94)$ & & \\
\hline Difficulty during labor & $3(0.81)$ & $7(13.07)$ & $10(13.89)$ & & \\
\hline \multicolumn{6}{|l|}{ Iron folate supplementation } \\
\hline Yes & $9(2.46)$ & $53(14.44)$ & $62(16.89)$ & \multirow{2}{*}{3.13} & \multirow{2}{*}{0.07} \\
\hline No & $76(20.70)$ & $229(62.40)$ & $305(83.11)$ & & \\
\hline \multicolumn{6}{|l|}{ Coffee consumption } \\
\hline Yes & $71(19.34)$ & $231(62.95)$ & $302(82.29)$ & \multirow{2}{*}{0.11} & 073 \\
\hline No & $14(3.81)$ & $51(13.90)$ & $65(17.71)$ & & 0.13 \\
\hline Khat chewing & & & & & \\
\hline Yes & $19(5.18)$ & $68(18.53)$ & $87(23.71)$ & 011 & 0.73 \\
\hline No & $66(17.98)$ & $214(58.31)$ & $280(76.29)$ & 0.11 & 0.13 \\
\hline Alcohol consumption & & & & & \\
\hline Yes & $0(0)$ & $3(0.82)$ & $3(0.82)$ & 0.91 & 034 \\
\hline No & $85(23.16)$ & $279(76.02)$ & $364(99.18)$ & 0.31 & \\
\hline
\end{tabular}

might be because of the geographical and sample size variations across the studies.

The prevalence of anemia (hemoglobin level $<11 \mathrm{~g} / \mathrm{dl}$ ) among pregnant women observed in this study was $23.16 \%$ [2]. This was agreed with the findings from the Oromia region (24.09\%) [25], Southern Ethiopia (23.2\%) [20], and China (23.5\%) [26]. However, it was much lower than similar studies reported from Southwest Ethiopia (31.4\%) [27], Rural communities of Eastern Ethiopia (43.9\%) [19], different parts of Ethiopia [13, 18, 28-30], Democratic Republic of Congo (53.4\%) [31], and India (62.3\%) [24]. On the other hand, it was higher than the findings reported from Adama Hospital (14.9\%) [32], St. Paul's Hospital (11.6\%) [33], Addis Ababa
(18.4\%) [34], the Central Zone of Tigray region Ethiopia (16.88\%) [35], Tanzania (18\%) [36], and Turkey(7\%) [37]. The possible explanation could be because of the study settings and the geographical variations. In addition to this, using different cut-off points and hemoglobin level measurements for anemia might also have resulted in variation of prevalence rate.

The current study also demonstrated that pregnant women who increased one meal frequency during pregnancy increased mean hemoglobin level by $0.41 \mathrm{~g} / \mathrm{dl}$. This finding was supported by the studies conducted in the rural communities of Eastern Ethiopia [19], the Northwestern Zone of Tigray [38], and the Central Zone of Tigray [35]. 
TABLE 4: Simple linear regression model predicting hemoglobin level among pregnant women in Jimma Zone, Southwest Ethiopia $(n=367)$.

\begin{tabular}{|c|c|c|c|c|c|}
\hline \multirow{2}{*}{ Model } & \multicolumn{2}{|c|}{$\begin{array}{l}\text { Unstandardized } \\
\text { coefficients }\end{array}$} & \multirow{2}{*}{$P$ value } & \multicolumn{2}{|c|}{$95 \%$ confidence interval } \\
\hline & $\beta$ & Std. error & & Lower bound & Upper bound \\
\hline \multicolumn{6}{|l|}{ Age (yrs) } \\
\hline $15-20$ & Ref & & & & \\
\hline $21-24$ & 0.07 & 0.21 & 0.74 & -0.35 & 0.50 \\
\hline $25-29$ & 0.14 & 0.17 & 0.39 & -.019 & 0.48 \\
\hline $30-34$ & -0.32 & 0.29 & 0.26 & -0.89 & 0.24 \\
\hline $35-49$ & 0.17 & 0.36 & 0.63 & -0.53 & 0.88 \\
\hline \multicolumn{6}{|l|}{ Religion } \\
\hline Muslim & 0.61 & 0.53 & 0.25 & -0.43 & 1.66 \\
\hline Orthodox Christian & 0.52 & 0.59 & 0.37 & -0.63 & 1.69 \\
\hline Protestant & Ref. & & & & \\
\hline \multicolumn{6}{|l|}{ Maternal education } \\
\hline Cannot read and write & Ref & & & & \\
\hline Elementary school & 0.01 & 0.18 & 0.99 & -0.35 & 0.37 \\
\hline Complete grade 8 & 0.51 & 0.24 & $0.03^{*}$ & 0.02 & 0.99 \\
\hline High school & 0.20 & 0.31 & 0.50 & -0.40 & 0.82 \\
\hline Collage and above & -0.05 & 0.29 & 0.84 & -0.63 & 0.52 \\
\hline Gravida & 0.02 & 0.04 & 0.54 & -0.06 & 0.11 \\
\hline \multicolumn{6}{|l|}{ Nausea and vomiting } \\
\hline Yes & 0.17 & 0.14 & 0.23 & -0.11 & 0.46 \\
\hline No & Ref & & & & \\
\hline \multicolumn{6}{|l|}{ Food taboo } \\
\hline Yes & 0.22 & 0.18 & 0.22 & -0.13 & 0.58 \\
\hline No & Ref & & & & \\
\hline \multicolumn{6}{|l|}{ Iron folate received } \\
\hline Yes & 1.28 & 0.18 & $<0.001^{*}$ & 0.92 & 1.64 \\
\hline No & Ref & & & & \\
\hline Meal frequency & 0.54 & 0.17 & $0.002^{*}$ & 0.20 & 0.88 \\
\hline Interpregnancy interval & 0.14 & 0.03 & $<0.001^{*}$ & 0.07 & 0.02 \\
\hline \multicolumn{6}{|l|}{ History of stillbirth } \\
\hline Yes & -0.86 & 0.25 & $0.001^{*}$ & -1.37 & -0.36 \\
\hline No & Ref. & & & & \\
\hline MUAC & 0.18 & 0.04 & $<0.001^{*}$ & 0.10 & 0.26 \\
\hline \multicolumn{6}{|l|}{ Consumed coffee } \\
\hline Yes & -1.22 & 0.17 & $<0.001^{*}$ & -1.57 & -0.86 \\
\hline No & Ref. & & & & \\
\hline \multicolumn{6}{|l|}{ Alcohol consumed } \\
\hline Yes & 0.20 & 0.80 & 0.80 & -1.38 & 0.88 \\
\hline No & Ref. & & & & \\
\hline \multicolumn{6}{|l|}{ Khat chewing } \\
\hline Yes & 0.03 & 0.17 & 0.85 & -0.30 & 0.36 \\
\hline No & Ref. & & & & \\
\hline \multicolumn{6}{|l|}{ Own fruits/vegetables } \\
\hline Yes & 0.60 & 0.14 & $<0.001^{*}$ & 0.32 & 0.88 \\
\hline No & Ref. & & & & \\
\hline
\end{tabular}

*Significant at $P<0.05$. 
TABLE 5: Multivariable linear regression model predicting hemoglobin level among pregnant women in Jimma Zone, Southwest Ethiopia $(n=367)$.

\begin{tabular}{|c|c|c|c|c|c|c|}
\hline \multirow{2}{*}{ Model } & \multicolumn{2}{|c|}{$\begin{array}{l}\text { Unstandardized } \\
\text { coefficients }\end{array}$} & \multirow[t]{2}{*}{$P$ value } & \multicolumn{2}{|c|}{ 95\% confidence interval } & \multirow{2}{*}{$\begin{array}{c}\text { Multicollinearity test } \\
{ }^{*} \text { VIF }\end{array}$} \\
\hline & $\beta$ & Std. error & & Lower bound & Upper bound & \\
\hline (Constant) & 9.89 & 0.95 & $<0.001$ & 8.02 & 11.76 & \\
\hline Meal frequency & 0.40 & 0.14 & 0.005 & 0.12 & 0.69 & 1.02 \\
\hline Interpregnancy interval & 0.08 & 0.03 & 0.007 & 0.02 & 0.15 & 1.03 \\
\hline History of still birth & -0.63 & 0.21 & 0.004 & -1.06 & -0.20 & 1.01 \\
\hline MUAC & 0.13 & 0.03 & $<0.001$ & 0.07 & 0.20 & 1.03 \\
\hline Consumed coffee & -1.00 & 0.16 & $<0.001$ & -1.31 & -0.68 & 1.05 \\
\hline Own fruits/vegetables & 0.55 & 0.12 & $<0.001$ & 0.31 & 0.79 & 1.02 \\
\hline Iron-folate supplement & 0.96 & 0.16 & $<0.001$ & 0.63 & 1.28 & 1.06 \\
\hline
\end{tabular}

$\beta$ : beta coefficient; MUAC: mid-upper arm circumference; $R^{2}: 0.332$.

This could be explained by the fact that increasing meal frequency during pregnancy enhances the probability of consuming iron-rich diversified diets and decreases the risk of anemia [20].

A one-year increment of the interpregnancy interval increased the mean hemoglobin level of a woman by $0.09 \mathrm{~g} / \mathrm{dl}$ in the current study. This observation was comparable with the findings of similar previous studies conducted in the Asossa zone of Ethiopia [39], Tigray region North Ethiopia [40], a systematic review and meta-analysis done in Ethiopia [30], and Tanzania [41]. This implied that a woman with a short interpregnancy interval was more likely to develop anemia during the current pregnancy than the others. This might be explained by the fact that close succession of pregnancies worsens the mother's nutritional status by depleting the total body iron of the women and become anemic, because of inadequate time to recover from the physiological stress of the proceeding pregnancy before becoming subject to the next [42].

This study also revealed that per one-centimeter increment of maternal mid-upper arm circumference measurement increases the mean hemoglobin level of a woman by $0.14 \mathrm{~g} / \mathrm{dl}$. The current finding was supported by the studies conducted in the urban area of Eastern Ethiopia [28], the Rural part of Jigjiga [29], pregnant women of Ethiopia [43], and Rural Oromia residents [25]. This might be because of the reason that undernourished pregnant women had a higher probability of being micronutrient deficient and anemic [44].

Likewise, being own fruits/vegetables in their garden was increasing maternal hemoglobin level by $0.5 \mathrm{~g} / \mathrm{dl}$ in this study. Other similar studies from different parts of Ethiopia, West Arsi Zone [17], and Central Ethiopia [45], Assosa zone, and Northwest Ethiopia (27) were comparable reported findings. This result might be because of the reason that women who own fruits/vegetables might be easily accessible and consume vitamin $\mathrm{C}$ and $\mathrm{A}$ source fruits/vegetables which are enhancers of gastrointestinal iron absorption [46]. The soluble complex compound formed by the reaction of vitamin A and $\beta$-carotene with iron in the lumen of the intestine may avoid the inhibitory effect of polyphenols and phytates on the absorption of iron [47].
In this study, we also observed that there was a negative linear association between pregnant women's mean hemoglobin level and having a history of stillbirth. Thus, having a history of stillbirth was decreased the mean hemoglobin level of the women by $0.63 \mathrm{~g} / \mathrm{dl}$. Our findings agreed with other study reports from Addis Ababa [48], the Democratic Republic of Congo [31], India [49], and England [50]. This might be explained by maternal anemia impaired placental function by increasing fetoplacental vasculogenesis and angiogenesis as an adaptive response. Thus, it decreases the nutrients supplementation to the fetus and leads to intrauterine growth retardation and stillbirth $[51,52]$.

Coffee consumption was another variable negatively associated with the hemoglobin level of the mother. Accordingly, coffee consumption during the current pregnancy decreased the hemoglobin level of pregnant women by $1.00 \mathrm{~g} / \mathrm{dl}$. This present result supported the report of previous studies from Central Ethiopia [45], Kacha Bira district of Southern Ethiopia [53], Durame town Ethiopia [54], Debremarkos Hospital [21], and Kartum Sudan [55]. This might be because of the reason that coffee contains phenolic acid such as a chlorogenic acid that inhibits the absorption of nonhaem iron, which is necessary for red blood cell production [56, 57].

In this study, analyses of different sociodemographic, obstetrics, and dietary factors that might be associated with the hemoglobin level of the women were carried out. Contrary to the previous findings, this study did not observe a statistically significant association between maternal hemoglobin level and factors like maternal age $[26,27,39,58,59]$, grand multiparty $[17,20,27,30,60]$, iron folate supplementations $[20,29,33,58,61]$, income/wealth index $[20,26,40,59,60]$, maternal education level [59, 61], and Khat chewing [19]. The research team recommends further study to evaluate the relationship between the aforementioned variables.

This study is not merely done without limitation. The information gathered was based on the report of the mother that it was likely to have social desirability and recall biases. Some predictors of anemia like some micronutrient deficiency and the presence of parasitic and malarial infections were not measured due to feasibility issues. 


\section{Conclusions}

Anemia was found to be a moderate public health problem in the study area. Meal frequency, interpregnancy interval, midupper arm circumference measurement, having fruits/vegetables, coffee consumption, and having a history of stillbirth were linearly associated with the hemoglobin level of pregnant women. Therefore, nutritional counseling should focus on the necessity of at least one extra meal, promotion of fruits/vegetable consumption, and improving the nutritional status of the women by care providers during antenatal care follow-up. Moreover, early screening and management of women with a history of stillbirth for anemia are also essential.

\section{Data Availability}

The data used to support the findings of this study are available from the corresponding author on reasonable request.

\section{Conflicts of Interest}

The authors declare that they have no conflicts of interest.

\section{Acknowledgments}

We thank Jimma University for its support during the research activities. We also extend our thanks to the Oromia health bureau, Jimma zone, and the two district health officials for their permission and support to conduct this study. We are grateful to the study participants, data collectors, supervisors, and colleagues for their cooperation and support during the research activities.

\section{References}

[1] WHO, Global nutrition targets 2025: anemia policy brief ( WHO/NMH/NHD/14.4), World health organization, Geneva, 2014, December 2020, http://apps.who.int/iris/ bitstream/10665/148556/1/WHO_NMH_NHD_14.4_eng .pdf?ua $=1$.

[2] WHO, Hemoglobin concentrations for the diagnosis of anemia and assessment of severity, World Health Organization, Geneva, 2011, (WHO/NMH/NHD/MNM/11.1). December 2020, http://www.who.int/vmnis/indicators/haemoglobin.pdf.

[3] G. A. Stevens, M. M. Finucane, L. M. de-Regil et al., "Global, regional, and national trends in haemoglobin concentration and prevalence of total and severe anaemia in children and pregnant and non- pregnant women for 1995-2011: a systematic analysis of population- representative data," The Lancet Global Health, vol. 1, no. 1, pp. e16-e25, 2013.

[4] J. Jung, M. M. Rahman, M. S. Rahman et al., "Effects of hemoglobin levels during pregnancy on adverse maternal and infant outcomes: a systematic review and meta-analysis," Annals of the New York Academy of Sciences, vol. 1450, no. 1, pp. 6982, 2019.

[5] C. Camaschella, "Iron-deficiency anemia," The New England Journal of Medicine, vol. 372, no. 19, pp. 1832-1843, 2015.

[6] WHO, The global prevalence of anemia in 2011, World health organization, Geneva, 2015 , December 2020 , http://9789241564960_eng.pdf;sequence=1 (who.int).
[7] M. W. Hentze, M. U. Muckenthaler, B. Galy, C. Camaschella, and C. Camaschella, "Two to tango: regulation of mammalian iron metabolism," Cell, vol. 142, no. 1, pp. 24-38, 2010.

[8] A. Stangret, A. Wnuk, G. Szewczyk, M. Pyzlak, and D. Szukiewicz, "Maternal hemoglobin concentration and hematocrit values may affect fetus development by influencing placental angiogenesis," The Journal of Maternal-Fetal \& Neonatal Medicine, vol. 30, no. 2, pp. 199-204, 2017.

[9] K. G. Dewey and B. M. Oaks, "U-shaped curve for risk associated with maternal hemoglobin, iron status, or iron supplementation," The American Journal of Clinical Nutrition, vol. 106, Supplement 6, pp. 1694S-1702S, 2017.

[10] N. Milman, "Oral iron prophylaxis in pregnancy: not too little and not too much!," Journal of Pregnancy, vol. 2012, 8 pages, 2012.

[11] WHO, WHO antenatal care recommendations for a positive pregnancy experience nutritional interventions update: multiple micronutrient supplements during pregnancy, WHO, Geneva, 2020, April 2021, https://www.who.int/ reproductivehealth/publications/maternal_perinatal_health/ anc-positive-pregnancy-experience/en/.

[12] Government of the Federal Democratic Republic of Ethiopia, National Nutrition Programme June 2013-June 2015, EFDR Government, Addis Ababa, Ethiopia, 2013, December 2020, https://extranet.who.int/nutrition/gina/es/printpdf/17834.

[13] Central Statistical Agency (Ethiopia) and ICF International, Ethiopia Demographic and Health Survey, CSA and ICF, Addis Ababa, Ethiopia, and Rockville, Maryland, USA, 2016.

[14] J. Warner, T. Stehulak, and L. Kasa, Woreda-Level Crop Production Rankings in Ethiopia: A Pooled Data Approach, International Food Policy Research Institute (IFPRI), Addis Ababa, Ethiopia, 2015.

[15] E. T. S. L. Wolde, L. Sera, and T. Melaku, "Sectorial transition dilemma of smallholder coffee farmers to light manufacturing industry in Jimma Zone, Oromia Region, Ethiopia," International Journal of Scientific and Research Publications, vol. 8, no. 11, 2018.

[16] FAO and FHI 360, Minimum dietary diversity for women: a guide for measurement, FAO, Rome, 2016, December 2020, http://www.fao.org/3/i5486e/i5486e.pdf.

[17] N. M. A. Obse, A. Mossie, and T. Gobena, "Magnitude of anemia and associated risk factors among pregnant women attending antenatal care in Shalla Woreda, West Arsi Zone, Oromia Region, Ethiopia," Ethiopian Journal of Health Sciences, vol. 23, no. 2, pp. 165-173, 2013.

[18] F. Z. E. Kefiyalew, E. Zemene, Y. Asres, and L. Gedefaw, “Anemia among pregnant women in Southeast Ethiopia: prevalence, severity and associated risk factors," BMC Research, vol. 7, no. 1, p. 771, 2014.

[19] H. B. Y. Kedir, Y. Berhane, and A. Worku, "Khat chewing and restrictive dietary behaviors are associated with anemia among pregnant women in high prevalence rural communities in eastern Ethiopia," PLoS One, vol. 8, no. 11, article e78601, 2013.

[20] M. Lebso, A. Anato, and E. Loha, "Prevalence of anemia and associated factors among pregnant women in Southern Ethiopia: a community-based cross-sectional study," PLoS One, vol. 12, no. 12, article e0188783, 2017.

[21] G. Kumera, K. Haile, N. Abebe, T. Marie, and T. Eshete, "Anemia and its association with coffee consumption and hookworm infection among pregnant women attending antenatal 
care at Debre Markos Referral Hospital, Northwest Ethiopia," PLoS One, vol. 13, no. 11, article e0206880, 2018.

[22] K. Acheampong, S. Appiah, D. Baffour-Awuah, and Y. S. Arhin, "Prevalence of anemia among pregnant women attending antenatal clinic of a selected hospital in Accra, Ghana," International Journal of Health Sciences and Research, vol. 8, no. 1, pp. 186-193, 2018.

[23] R. G. Viveki, A. B. Halappanavar, P. R. Viveki, S. B. Halki, V. S. Maled, and P. S. Deshpande, "Prevalence of anaemia and its epidemiological determinants in pregnant women," Al Ameen Journal of Medical Sciences, vol. 5, no. 3, pp. 216-223, 2012.

[24] R. Suryanarayana, M. Chandrappa, A. N. Santhuram, S. Prathima, and S. Sheela, "Prospective study on prevalence of anemia of pregnant women and its outcome: a community based study," Journal of Family Medicine and Primary Care, vol. 6, no. 4, pp. 739-743, 2017.

[25] K. Zillmer, A. Pokharel, K. Spielman et al., "Predictors of anemia in pregnant women residing in rural areas of the Oromiya region of Ethiopia," BMC Nutrition, vol. 3, no. 1, p. 65, 2017.

[26] on behalf of the Gestational diabetes mellitus Prevalence Survey (GPS) study Group, L. Lin, Y. Wei et al., "Prevalence, risk factors and associated adverse pregnancy outcomes of anaemia in Chinese pregnant women: a multicentre retrospective study," BMC Pregnancy and Childbirth, vol. 18, no. 1, p. 111, 2018.

[27] M. A. Demissie, "Prevalence of anemia and risk factors among pregnant mothers attending antenatal care at Jimma University Specialized Hospital, South-West Ethiopia," Journal of Health, Medicine and Nursing, vol. 65, pp. 30-36, 2019.

[28] K. Addis Alene and A. Mohamed Dohe, "Prevalence of anemia and associated factors among pregnant women in an urban area of Eastern Ethiopia," Anemia, vol. 2014, Article ID 561567, 7 pages, 2014.

[29] S. Gebretsadik Bereka, A. N. Gudeta, M. Abate Reta, and L. Assefa Ayana, "Prevalence and associated risk factors of anemia among pregnant women in rural part of JigJiga City, Eastern Ethiopia: a Cross Sectional study," Journal of Pregnancy and Child Health, vol. 4, no. 3, 2017.

[30] G. M. Kassa, A. A. Muche, A. K. Berhe, and G. A. Fekadu, "Prevalence and determinants of anemia among pregnant women in Ethiopia; a systematic review and meta-analysis," BMC Hematology, vol. 17, no. 1, p. 17, 2017.

[31] B. Tandu-Umba and A. M. Mbangama, "Association of maternal anemia with other risk factors in occurrence of great obstetrical syndromes at university clinics, Kinshasa, DR Congo," BMC Pregnancy and Childbirth, vol. 15, no. 1, p. 183, 2015.

[32] B. Ayano and B. Amentie, "Assessment of prevalence and risk factors for anemia among pregnant mothers attending Anc clinic at Adama Hospital Medical Collage, Adama, Ethiopia, 2017," Journal of Gynecology and Obstetrics, vol. 6, no. 3, pp. 31-39, 2018.

[33] A. Gebreweld and A. Tsegaye, "Prevalence and factors associated with anemia among pregnant women attending antenatal clinic at St. Paul's Hospital Millennium Medical College, Addis Ababa, Ethiopia," Advances in Hematology, vol. 2018, 8 pages, 2018.

[34] B. Alemu and D. Gashu, "Association of maternal anthropometry, hemoglobin and serum zinc concentration during pregnancy with birth weight," Early Human Development, vol. 142, article 104949, 2020.
[35] T. Grum, E. Brhane, S. Hintsa, and G. Kahsay, "Magnitude and factors associated with anemia among pregnant women attending antenatal care in public health centers in central zone of Tigray region, northern Ethiopia: a cross sectional study," BMC Pregnancy and Childbirth, vol. 18, no. 1, p. 433, 2018.

[36] G. Stephen, M. Mgongo, T. Hussein Hashim, J. Katanga, B. Stray-Pedersen, and S. E. Msuya, "Anaemia in pregnancy: prevalence, risk factors, and adverse perinatal outcomes in Northern Tanzania," Anemia, vol. 2018, 9 pages, 2018.

[37] T. Yildirim, A. Yalcin, V. Atmis et al., "The prevalence of anemia, iron, vitamin $B_{12}$, and folic acid deficiencies in community dwelling elderly in Ankara, Turkey," Archives of Gerontology and Geriatrics, vol. 60, no. 2, pp. 344-348, 2015.

[38] A. Gebre and A. Mulugeta, "Prevalence of anemia and associated factors among pregnant women in North Western zone of Tigray, Northern Ethiopia: a cross-sectional study," Journal of Nutrition and Metabolism, vol. 2015, 7 pages, 2015.

[39] A. Abay, H. W. Yalew, A. Tariku, and E. Gebeye, "Determinants of prenatal anemia in Ethiopia," Archives of Public Health, vol. 75, no. 1, p. 51, 2017.

[40] H. T. D. G. Hailemichael, G. T. Debelew, H. B. Alema, M. G. Weldu, and K. H. Misgina, "Determinants of adverse birth outcome in Tigrai region, North Ethiopia: hospital-based case-control study," BMC Pediatrics, vol. 20 , no. 1, pp. 10 19, 2020.

[41] A. Lilungulu, D. Matovelo, A. Kihunrwa, and B. Gumodoka, "Spectrum of maternal and perinatal outcomes among parturient women with preceding short inter-pregnancy interval at Bugando Medical Centre, Tanzania," Maternal Health, Neonatology and Perinatology, vol. 1, no. 1, p. 1, 2015.

[42] A. R.-B. A. Conde-Agudelo, A. Rosas-Bermudez, F. Castaño, and M. H. Norton, "Effects of birth spacing on maternal, perinatal, infant, and child health: a systematic review of causal mechanisms," Studies in Family Planning, vol. 43, no. 2, pp. 93-114, 2012.

[43] S. Ghosh, K. Spielman, M. Kershaw et al., "Nutrition-specific and nutrition-sensitive factors associated with mid-upper arm circumference as a measure of nutritional status in pregnant Ethiopian women: implications for programming in the first 1000 days," PLoS One, vol. 14, no. 3, article e0214358, 2019.

[44] A. Workicho, T. Belachew, S. Ghosh, M. Kershaw, C. Lachat, and P. Kolsteren, "Burden and determinants of undernutrition among young pregnant women in Ethiopia," Maternal \& Child Nutrition, vol. 15, no. 3, article e12751, 2019.

[45] B. S. Deriba, G. A. Bulto, E. T. Bala, and R. T. Souza, "Nutritional-related predictors of anemia among pregnant women attending antenatal care in Central Ethiopia: an unmatched case-control study," BioMed Research International, vol. 2020, 9 pages, 2020.

[46] EFSA NDA Panel (EFSA Panel on Dietetic Products NaA, "Scientific Opinion on the substantiation of a health claim related to vitamin $\mathrm{C}$ and increasing non haem iron absorption pursuant to Article 14 of Regulation (EC) No 1924/2006," EFSA Journal, vol. 12, no. 1, p. 9, 2014.

[47] María N. García-Casal, M. Layrisse, L. Solano et al., "Vitamin $\mathrm{A}$ and $\beta$-Carotene can improve nonheme iron absorption from rice, Wheat and corn by humans," The Journal of Nutrition, vol. 128, no. 3, pp. 646-650, 1998.

[48] Y. Getiye and M. Fantahun, "Factors associated with perinatal mortality among public health deliveries in Addis Ababa, 
Ethiopia, an unmatched case control study," BMC Pregnancy and Childbirth, vol. 17, no. 1, p. 245, 2017.

[49] A. Patel, A. A. Prakash, P. K. Das, S. Gupta, Y. V. Pusdekar, and P. L. Hibberd, "Maternal anemia and underweight as determinants of pregnancy outcomes: cohort study in eastern rural Maharashtra, India," BMJ Open, vol. 8, no. 8, article e021623, 2018.

[50] M. C. D. Nair, D. Churchill, S. Robinson, C. Nelson-Piercy, S. J. Stanworth, and M. Knight, “Association between maternal haemoglobin and stillbirth: a cohort study among a multiethnic population in England," British Journal of Haematology, vol. 179, no. 5, pp. 829-837, 2017.

[51] J. E. Lawn, H. Blencowe, P. Waiswa et al., "Stillbirths: rates, risk factors, and acceleration towards 2030," The Lancet, vol. 387, no. 10018 , pp. 587-603, 2016.

[52] F. C. Chu, S. Shen-Wen Shao, L.-M. Lo, T. Hsieh, and T. H. Hung, "Association between maternal anemia at admission for delivery and adverse perinatal outcomes," Journal of Chinese Medical Association, vol. 83, no. 4, pp. 402-407, 2020.

[53] M. S. Teshome, D. H. Meskel, and B. Wondafrash, "Determinants of anemia among pregnant women attending antenatal care clinic at public health facilities in Kacha Birra District, Southern Ethiopia," Journal of Multidisciplinary Healthcare, vol. Volume 13, pp. 1007-1015, 2020.

[54] F. Weldekidan, M. Kote, M. Girma, N. Boti, and T. Gultie, "Determinants of Anemia among Pregnant Women Attending Antenatal Clinic in Public Health Facilities at Durame Town: Unmatched Case Control Study," Anemia, vol. 2018, Article ID 8938307, 8 pages, 2018.

[55] N. E. B. Mohamed and R. H. A. Hassan, "Prevalence and factors associated with anemia among pregnant women attending ante-natal clinic in the second and third trimesters at Soba University Hospital, Khartoum State, Sudan (2018-2019)," International Journal of Health Sciences and Research, vol. 10, no. 8, pp. 195-204, 2020.

[56] W. Tsedeke, "Effects of caffeine on health and nutrition: a review food science and quality," Management, vol. 30, pp. 59-65, 2014.

[57] R. F. Hurrell, M. Reddy, and J. D. Cook, "Inhibition of nonhaem iron absorption in man by polyphenolic-containing beverages," British Journal of Nutrition, vol. 81, no. 4, pp. 289295, 1999.

[58] S. Ononge, O. Campbell, and F. Mirembe, "Haemoglobin status and predictors of anaemia among pregnant women in Mpigi, Uganda," BMC Research Notes, vol. 7, no. 1, article $712,2014$.

[59] H. A. Chowdhury, K. R. Ahmed, F. Jebunessa, J. Akter, S. Hossain, and M. Shahjahan, "Factors associated with maternal anaemia among pregnant women in Dhaka city," BMC Women's Health, vol. 15, no. 1, pp. 1-6, 2015.

[60] L. Karaoglu, E. Pehlivan, M. Egri et al., "The prevalence of nutritional anemia in pregnancy in an east Anatolian province, Turkey," BMC Public Health, vol. 10, no. 1, article 329, 2010.

[61] Y. Gebregzabiherher, A. Haftu, S. Weldemariam, and H. Gebrehiwet, "The prevalence and risk factors for low birth weight among term newborns in Adwa General Hospital, Northern Ethiopia," Obstetrics and Gynecology International, vol. 2017, 7 pages, 2017. 